\title{
Prospective Mobility, Fairness, and the Demand for Redistribution
}

\author{
Christina M. Fong*
}

February 26, 2006

Abstract. People who believe that their society has few impediments to upward mobility tend to oppose governmental redistribution. This is true even among the poor. Is this because people with this belief expect to be well off in the future, and hence oppose redistribution on self-interested grounds? Or is it because they believe that the less well off have not made the effort to move up, and therefore are morally undeserving of support? This paper uses quantitative sensitivity analysis to examine the robustness of the evidence for each of these views. It finds that the effect of prospective mobility is sensitive to measurement error in current income. In contrast, there is robust support for the view that beliefs about moral worthiness matter.

JEL Codes: J62, D31, D63

Keywords: prospects of upward mobility, redistributive politics, social preferences, beliefs, errors-in-variables

*Department of Social and Decision Sciences, Carnegie Mellon University, Pittsburgh, PA 15213. tel: 412-268-8168, email: fong2@andrew.cmu.edu.

I am indebted to Steven Klepper and Sam Bowles for substantial comments. I am also grateful to Peter Thompson, John Miller, Ada Ferrer-i-Carbonell, George Loewenstein, Robyn Dawes, Julie Downs, Toby Davis, Andreas Bergh, Jeff Dominitz, Alois Stutzer, and participants of various seminars for helpful comments and discussion. 


\section{INTRODUCTION}

People who believe that there are few impediments to upward mobility tend to oppose governmental redistribution. This is true even of people with quite modest incomes who seemingly might benefit from these programs. For example, according to a national survey of the United States by the Gallup Organization (Gallup Organization (1998)), $60 \%$ of respondents who say that there is plenty of opportunity to get ahead oppose redistribution of wealth by taxation of the rich, while $40 \%$ support it. ${ }^{1}$ In contrast, only $32 \%$ of those who do not believe that there is plenty of opportunity to get ahead oppose redistribution of wealth by taxation of the rich. Strikingly, even among those with annual pre-tax household incomes below $\$ 30,000,50 \%$ oppose taxation of the rich if they believe that there is plenty of opportunity to get ahead.

Is this because people who believe that upward mobility is unimpeded expect to be well off in the future, and hence oppose redistribution on self-interested grounds, as suggested by Hirschman (1973) and others? Or is it because they believe that the poor made little effort to move up and are therefore morally undeserving of support, and that the rich worked hard for their success and therefore deserve low taxes? ${ }^{2}$ The key difference between these views concerns the assumptions they make about preferences. The first view adopts the conventional assumption of self-regarding

\footnotetext{
${ }^{1}$ See Appendix B for question wording and summary statistics.

${ }^{2}$ See Kluegel and Smith (1986) for an early study on this issue using nationally representative data.
} 
preferences. Following Benabou and Ok (2001) I refer to this as the prospects of upward mobility hypothesis. In contrast, according to the second view, people readily support redistribution from which they would not personally benefit, as long as the recipients are considered morally worthy. I refer to this as the fairness view of mobility and redistributive politics.

Using data from the Gallup Organization, this paper asks: which is more likely to have a true effect on opposition to redistribution, prospective mobility or beliefs that effort levels rather than luck cause wealth and poverty? It is not difficult to produce empirical results in which both prospective mobility and beliefs about the causes of wealth and poverty appear to have the expected effects. However, the effect of prospective mobility is quite sensitive to specification while the effects of beliefs about the worthiness of recipients are quite robust. Indeed, in all previous research claiming to support the prospective mobility hypothesis, the measures of prospective mobility are highly correlated with current income and have sensitive effects. For example, Ravallion and Lokshin (2000) find that in 1990s Russia, those who said they expect to live worse in the next twelve months than today were more in favor of "restricting the incomes of the rich" compared to those who said they expect to live better in the next twelve months. However, they report that the effect of this measure is not significant after controlling for other socioeconomic variables. They cite the correlation between current income and subjective mobility as a clear 
reason for this. Graham and Pettinato (2002) also find negative effects of subjective mobility on support for redistribution. However, they do not show that these effects remain significant after controlling for current income.

Alesina and La Ferrara (2004) use data from the General Social Survey and the Panel Study of Income Dynamics to show that expected mobility predicted from current income plus either geographical location or year of participation in the survey has a negative effect on a measure of support for redistribution. The effects of this measure of expected future income are sensitive to how the dependent variable is measured. It has the expected effect on some measures, no effect on others, and an effect in the wrong direction on another. They interpret the coefficients that have the correct sign as evidence in favor of the prospective mobility hypothesis.

In contrast, evidence for the fairness view appears robust. First, there is causal evidence from several randomized experiments. These experiments show that randomly varied information about the moral worthiness of recipients of public redistribution and of private charity has significant effects in the expected directions on beliefs about how hard the recipients work, on attitudes to governmental redistribution to them, and on donations of real money to them (Heclo (1986); Gilens (1999); Eckel and Grossman (1996); Fong (2004)). These effects can be quite large. For instance, subjects give roughly three times more to the American Red Cross than to anonymous subjects, presumably because the Red Cross is a morally worthy recipient (Eckel and 
Grossman (1996)). A different experiment using attitudinal survey data randomly varied the wording of a question about support for public redistribution. One version of the survey asked about spending on "welfare" while others asked about spending on "assistance for the poor," or "caring for the poor." In that experiment, $41 \%$ of respondents stated that there is too much spending on welfare and $25 \%$ stated that there is too little. In contrast, only $11 \%$ and $7 \%$ of the respondents said that there is too much spending on assistance for and caring for the poor, respectively, while $64 \%$ and $69 \%$ said that there is too little. One interpretation of this finding is that this survey experiment was conducted at a time when "welfare" referred primarily to the politically unpopular AFDC program, whose recipients were perceived as morally unworthy (Heclo (1986)).

Second, in addition to these results from randomized experiments, non-causal attitudinal survey evidence shows a robust association between opposition to redistribution and beliefs that poverty and wealth are caused by effort levels rather than luck. Missing variables tests show that these correlations cannot be explained by missing measures of pecuniary interests in redistribution (Fong (2001)).

Why is the evidence for the prospects of upward mobility hypothesis so sensitive? One possibility is error in the measures of prospective mobility, which would lead to attenuation bias in its coefficient. Another possibility is error in the dependent measures of demands for redistribution, which could lead to imprecision in the estimates. 
Both of these problems could cause sensitivity via Type II errors, leading us to fail to find support for the prospective mobility hypothesis when it is true. However, using measures and specifications that rule out Type II errors, this paper shows that there is a more serious problem that may cause Type I errors, leading us to find support for the prospective mobility hypothesis when it is false.

This paper points out that an important source of sensitivity of the effect of prospective mobility is its correlation with current income, which is notoriously poorly measured. The paper presents a quantitative analysis of the sensitivity of the coefficients to measurement error in current income. It uses measures and specifications that yield highly significant effects. It then shows that even when measures of prospective mobility have highly significant effects, these effects are sensitive to measurement error in current income. In contrast, performing this quantitative sensitivity analysis on the fairness models shows that the effects of beliefs about the causes of income are quite robust to measurement error in current income. Appendix A extends the analysis to check whether measurement error in prospective mobility or beliefs about the causes of income, in combination with measurement error in current income, might cause important changes in the results. It does not.

This paper also shows that the effects of race and gender are roughly equivalent in size and robustness. This may surprise readers who consider race to be one of the most important determinants of demands for redistribution. There is little doubt 
that race plays an important role in American politics over welfare, i.e., means-tested redistribution to the poor (Gilens (1999); Luttmer (2001)). However, welfare is a small part of redistributive expenditures and revenues. The results presented below suggest that the importance of race relative to gender in determining demands for general redistribution is an open question.

Analyzing biases from measurement error in current income is important because both the fairness and prospective mobility hypotheses address a well-known puzzle; they explain opposition to redistribution when current income fails to do so. Canonical models of the demand for redistribution argue that an individual's demand for redistribution is determined by his or her current income (Roberts (1977)). The puzzle is that although current income does matter, it matters surprisingly little from the canonical perspective. ${ }^{3}$ The value of the prospective mobility and fairness hypotheses lies in their potential to explain demands for redistribution conditional on current income. If estimated effects of prospective mobility are due primarily to our inability to separate its effects from the effects of current income, then the evidence fails on a point that is critical to the theory.

It is also important to analyze evidence from non-causal social survey data more carefully than has been done in the past, despite the obvious drawbacks of such data, including the possibility that both prospecitve mobility and beliefs about worthiness

\footnotetext{
${ }^{3}$ See, among others, Meltzer and Richard (1981), Roemer (1998), Putterman (1997), and Benabou and Ok (2001) for discussions of and some answers to this puzzle.
} 
are endogenous to individual demands for redistribution. ${ }^{4}$ The reason is simple: despite its flaws, evidence from such data has played an influential role in establishing the plausibility of both the prospective mobility and the fairness hypotheses. If we think of non-causal social survey evidence as a demonstrator of plausibility, then the contribution of this paper is to point out that the fairness hypothesis has been shown to be plausible while the prospective mobility hypothesis has not. A natural next step is to generate causal evidence, e.g. from randomized experiments. For the fairness hypothesis, some studies (discussed above) have already taken this step.

The rest of the paper is organized as follows. Sections 2 and 3 discuss the specification and empirical approach. Section 4 summarizes the measures and establishes the validity of the measure of prospective mobility using additional data from the National Survey of Midlife Development in the U.S. 1995-1996. Section 5 presents both informal and quantitative sensitivity analyses for the case where current income is the only poorly measured regressor. Section 6 concludes. Appendix A extends the analysis to the case where there are two poorly measured regressors - namely, current income and either prospective mobility or beliefs about worthiness.

\footnotetext{
${ }^{4}$ Prospective mobility may be endogenous if people who oppose redistribution for other reasons, such as fairness concerns, work harder to distinguish themselves socially from the poor, especially when the poor are perceived as lazy and undeserving. Self-reported beliefs about worthiness may be endogenous if people who oppose redistribution for other reasons, such as selfishness, say they believe the poor are lazy to justify their preference.
} 


\section{SpecificAtion}

Following Benabou and Ok (2001) , I specify the effect of prospective mobility on an individual's demand for redistribution as follows. Taxes are voted on in the first time period and are effective for $t=1, \ldots, T$ time periods. Individuals choose the tax rate to maximize the present value of the stream of incomes over these time periods. The tax-transfer scheme is a proportional income tax with a lump sum transfer. Individuals choose the tax rate to maximize

$$
U_{i, t}=\sum_{t=1}^{T} \delta^{t} Y_{i}^{t}(1-\tau)+\sum_{t=1}^{T} \delta^{t} \bar{Y}^{t} \tau
$$

where $Y_{i}^{t}, \bar{Y}^{t}$, and $\delta^{t}$ are, respectively, individual income, average income, and the discount factor in time $t$, and $\tau$ is the tax rate for all $t=1, \ldots T$ time periods. In this specification, an individual will prefer a tax rate of zero if the present value of his or her income stream is greater than the present value of the annual average income. Empirically, we should observe that individuals who expect higher future incomes demand less redistribution, controlling for current income.

Regarding the fairness view, there is a large literature on social preferences that debates how best to formalize fairness-seeking behavior (Rabin (1993); Levine (1998); Dufwenberg and Kirchsteiger (1999); Falk and Fischbacher (1998); Bolton and Ockenfels (2000); Fehr and Schmidt (1999); Charness and Rabin (2002); Rotemberg (2004)). Fairness concerns have also been modeled in the context of redistributive politics 
(Alesina and Angeletos (2005); Benabou and Tirole (forthcoming)). Although the models differ, the similarities are more important than the differences for the purposes of this paper. There is broad support in the literature for the idea that, for various fairness motives, people who believe the poor are lazy and people who believe that the rich are industrious will demand less redistribution.

2.1. Three models to be estimated. I will estimate three models. Model 1 tests the prospective mobility model, predicting opposition to redistribution with a proxy for expected future income. Model 2a tests the fairness model, predicting opposition to redistribution with the belief that poverty is caused by lack of effort rather than bad luck. For additional robustness testing, I estimate a third model, Model 2b, which predicts opposition to redistribution with the belief that wealth is caused by strong effort rather than good luck. All three models control for pre-tax household income, age, age squared, race, gender, marital status and household size.

When reasonable, it is important to avoid including variables - such as education and occupation - that may have effects on demands for redistribution that should be attributed to current or expected future income. ${ }^{5}$ However, I control for race and gender because researchers have argued that they may have effects on individual

\footnotetext{
${ }^{5}$ Some might argue that education should be included because it "enlightens" people about social and economic constraints. This effect may operate in different directions in different fields of study. In unreported analyses, I found the effects of education to be quite sensitive to measurement error in current income. This is consistent with the idea that education is an indicator of current and future financial security.
} 
demands for redistribution that are independent of the effects of current and expected future income. I control for age and age squared to control for the individual's stage in the life cycle. Finally, I include marital status and household size because, for a given household income, larger households are poorer. Note, however, that I have conducted the entire analysis without including marital status and household size (unreported). This had no noteworthy effects on the results.

The three models have the following form:

$$
R=\sum_{i=1}^{K} \alpha_{i}^{*} x_{i}^{*}+v
$$

where $^{*}$ indicates true unobserved variables and true parameters, $v$ is the error in the true regression model, and all of the assumptions of the classical normal regression model are satisfied. $R$ is the observed measure of opposition to redistribution. There are eight independent variables. Seven are always the same: $x_{K}^{*}$ is current income and $x_{1}^{*}, \ldots x_{K-2}^{*}$ are age, age squared, household size, and dummies for being, respectively, white, male and married. The remaining variable, $x_{K-1}^{*}$, differs across the models. In Model 1 it is expected future income, in Model 2a it is the belief that lack of effort rather than bad luck causes poverty, and in Model $2 \mathrm{~b}$ it is the belief that strong effort rather than good luck causes wealth.

I assume that $x_{K-1}^{*}$ and $x_{K}^{*}$ may be measured with error and $x_{1}^{*}, \ldots x_{K-2}^{*}$ are not. Specifically, let 


$$
\begin{gathered}
x_{K-1}=x_{K-1}^{*}+u_{1} \text { with } u_{1} \sim N\left[0, V_{1}\right] \\
x_{K}=x_{K}^{*}+u_{2} \text { with } u_{2} \sim N\left[0, V_{2}\right]
\end{gathered}
$$

where $x_{K-1}$ and $x_{K}$ are observed measures of $x_{K-1}^{*}$ and $x_{K}^{*}$, and $u_{1}$ and $u_{2}$ are measurement errors. Assume that $u_{1}$ and $u_{2}$ are classical measurement errors in the sense that they are uncorrelated with each other, with $v$, and with the true independent variables. In addition, assume that the true independent variables have zero means. Demeaning the independent variables is not necessary. This assumption merely simplifies the presentation of the regression model by eliminating the constant term.

\section{Empirical Approach}

The econometric problem of primary concern in this paper is that measurement error in current income may bias the coefficients on the key regressors upward in magnitude. This kind of bias may lead us to commit a Type I error. In contrast, measurement error in $x_{K-1}$ is a secondary concern which does not change the conclusions of this paper. By itself, measurement error in $x_{K-1}$ cannot cause the serious form of sensitivity addressed in this paper because it will merely attenuate the estimated coefficient on $x_{K-1}$ toward zero, and I use measures that already have significant effects despite 
such attenuation bias. Sections 3 and 5 present the simple case in which there is a single poorly measured regressor - namely, current income. Appendix A addresses the case in which both current income and $x_{K-1}$ may be measured with error.

One approach to assessing the seriousness of the measurement error biases is to calculate bounds on the true regression coefficients. ${ }^{6}$ When only one variable is measured with error, the true regression coefficients are bounded by the ordinary least squares estimates, and the normalized coefficients obtained by estimating the reverse regression of the poorly measured independent variable on the dependent variable and the other independent variables and then solving for the original dependent variable on the left hand side. ${ }^{7}$ If these bounds have the same sign, then this is reassuring in the sense that our estimated coefficient at least tells us the correct sign of the true coefficient. If the bounds have different signs, then the true coefficient may be zero or may even have the opposite sign from the estimated coefficient.

3.1. Quantitative sensitivity analysis. When only one regressor is measured with error and the bounds have opposite signs, there is a simple way to take the analysis a step further. One can ask: For any given value of $\alpha_{K-1}^{*}$ that falls within the bounds, how much measurement error in current income is needed to generate the

\footnotetext{
${ }^{6}$ An alternative option is the instrumental variables approach. The difficulty with this approach is finding a suitable instrument for current income in a data set with the requisite data.

${ }^{7}$ See Klepper and Leamer (1984) on bounding estimates when all regressors are measured with error and Kamlet, Klepper and Frank (1993) for an applied discussion of bounding coefficients and calculating additional diagnostics when various amounts of measurement error in specific regressors are assumed.
} 
estimated coefficient $\alpha_{K-1}$ ? An interesting case is when the bounds on $\alpha_{K-1}^{*}$ differ in sign. In this case, we can calculate how much measurement error in current income would be needed to generate the estimated coefficient $\alpha_{K-1}$ if $\alpha_{K-1}^{*}$ were zero. If we believe that the measurement error in current income may be at least this high, then the estimated coefficient is meaningless in the sense that we do not even know if it has the correct sign. The following sub-section develops these calculations in more detail.

Calculating the robustness statistic from observables in the data. We want to calculate the amount of measurement error in income needed to explain $\alpha_{K-1}$ when $\alpha_{K-1}^{*}=0$.

To do this, first note that from Chow (1957), we know that when $x_{k}$ is the only regressor measured with error, the biases in $\alpha_{K}$ and $\alpha_{K-1}$ are

$$
\begin{gathered}
\alpha_{K}-\alpha_{K}^{*}=\frac{-V_{2} \alpha_{K}^{*}}{\sigma_{K}^{*}+V_{2}} \\
\alpha_{K-1}-\alpha_{K-1}^{*}=\frac{V_{2} \gamma_{K-1} \alpha_{K}^{*}}{\sigma_{K}^{*}+V_{2}}
\end{gathered}
$$

where the $\alpha_{K-1}$ and $\alpha_{K}$ are the estimated coefficients obtained by using the observed regressors to estimate the model, $\alpha_{K}^{*}$ and $\alpha_{K-1}^{*}$ are the true coefficients that one could obtain if it were possible to estimate the model with no measurement 
error, $\sigma_{K}^{*} \equiv V\left(x_{K}^{*} \mid x_{1}^{*}, x_{2}^{*}, \ldots, x_{K-1}^{*}\right)$, and $\gamma_{K-1}$ is defined by the auxiliary regression $E\left(x_{K}^{*} \mid x_{1}^{*}, x_{2}^{*}, \ldots, x_{K-1}^{*}\right)=\sum_{i=1}^{K-1} \gamma_{i} x_{i}^{*}$. Note that the $\gamma_{i}$ are observable in this case because estimating them in a regression that predicts $x_{K}$ instead of $x_{K}^{*}$ does not bias them.

Next, we set $\alpha_{K-1}^{*}=0$, express the unobservables in terms of observables, and solve for $V_{2}$. Setting $\alpha_{K-1}^{*}=0$ and combining (5) and (6) yields

$$
\alpha_{K-1}=\frac{V_{2} \gamma_{K-1} \alpha_{K}}{\sigma_{K}^{*}} .
$$

To express $\sigma_{K}^{*}$ in terms of observables, let $V\left(x_{K} \mid x_{1}^{*}, x_{2}^{*}, \ldots, x_{K-1}\right) \equiv \widehat{\sigma}_{K}$. Note that

$$
\widehat{\sigma}_{K}=\sigma_{K}^{*}+V_{2} .
$$

Substituting $\widehat{\sigma}_{K}-V_{2}$ for $\sigma_{K}^{*}$ and solving for $V_{2}$ yields:

$$
V_{2}=\frac{\widehat{\sigma}_{K}\left(\alpha_{K-1}\right)}{\alpha_{K-1}+\alpha_{K} \gamma_{K-1}} .
$$

Finally, let us express the resulting value of $V_{2}$ as a fraction of the variance in current income and refer to the resulting statistic as the robustness of $\alpha_{K-1}$. The 
robustness of $\alpha_{K-1}$ is thus:

$$
\frac{V_{2}}{V\left(x_{K}\right)}=\frac{\widehat{\sigma}_{K}}{\left(\frac{\alpha_{K} \gamma_{K-1}}{\alpha_{K-1}}+1\right) V\left(x_{K}\right)}
$$

The definitions of the terms that appear in Equation (10) are summarized in Table 1.

Note that we can also perform this exercise for values of $\alpha_{K-1}^{*}$ other than zero. Suppose $C$ is a particular value of $\alpha_{K-1}^{*}$ that falls within the bounds on $\alpha_{K-1}^{*}$. It is straightforward to show that the robustness of $\alpha_{K-1}$ when $\alpha_{K-1}^{*}=C$ is:

$$
\frac{V_{2}}{V\left(x_{K}\right)}=\frac{\widehat{\sigma}_{K}}{\left(\frac{\alpha_{K} \gamma_{K-1}}{\alpha_{K-1}-C}+1\right) V\left(x_{K}\right)} .
$$

\section{Measures}

I use data from the Gallup Organization Social Audit titled "Haves and Have-Nots" (Gallup Organization, 1998), a national sample of the United States containing 5001 respondents of the ages 18 years and older. There are three suitable measures of opposition to redistribution in the data set, all of them binary: 1) opposition to versus support for taxation of the rich, 2) opposition to versus support for government redistribution to the poor, and 3) opposition to versus acceptance of inequality. ${ }^{8}$ In

\footnotetext{
${ }^{8}$ Throughout the analysis I code "don't know" responses as missing. This corresponds to assumptions that people have well-formed preferences, beliefs, and expectations.
} 
this paper, I use the sum of these questions, standardized to a mean of zero and standard deviation of one. Aggregating responses to multiple questions increases the measurement reliability of the dependent measure which, in turn, decreases the residual variance and increases the precision of the estimates in ordinary least squares equations. This reduces sensitivity due to measurement error in the dependent variable, helping us focus on sensitivity due to measurement error in the regressors.

I assume a cardinal interpretation of the dependent measure and analyze it with ordinary least squares. In the first part of Section 5, this is purely for convenience in reporting and interpreting the results; it makes little difference to the results if ordered probit is used instead. In Section 5.1, however, the cardinal interpretation is necessary because the quantitative sensitivity analysis has not been developed for ordered probit or logit models.

The Gallup data set has a measure of current annual pre-tax household income that is measured in nine categories. I specify it as a single measure by representing each category with an estimate of the median income of the people in that category. I obtain the category medians for income levels up to $\$ 100,000$ from the concurrent March Supplement to the Current Population Survey. ${ }^{9}$ For income levels greater than $\$ 100,000$, I estimate the category medians using data on the distribution of income

\footnotetext{
${ }^{9}$ For each income category in the Gallup survey, there is a set of smaller income categories in the CPS. For each Gallup income category, we use the CPS income category cutoff point that is closest to the 50th percentile.
} 
up to $\$ 250,000$ or more from the 2000 Current Population Survey. ${ }^{10}$ Note that I have also conducted the entire analysis (including that presented in Appendix A) using category mid-points and dropping the highest income category (unreported). This produced similar results and did not change the conclusions of the paper.

I define beliefs about the causes of income as continuous variables ranging from zero to one. For some of the results, this cardinal interpretation is unnecessary because I use dummy variables for the belief that only effort matters and the belief that both luck and effort matter. However, in Section 5.1, it is necessary to specify beliefs as a single variable. I set this variable equal to zero if only luck matters, 0.5 if both luck and effort matter, and 1 if only effort matters.

Note that with the exception of race and gender, the important variables in this analysis are continuous. When continuos variables are measured in categories, there are two sources of error. One is classification error - measuring the variable in the wrong category. The other is the difference between the value of the true continuous variable and the value of the broad category that it belongs to. It is possible that classification error is small relative to the latter type of error. In fact, a major justification for measuring continuous variables such as income with categories is that the classification error will be relatively small.

\footnotetext{
${ }^{10}$ See Table HINC-07 of the Detailed Household Income Tables: 2000, from the 2001 Current Population Survey March Supplement release.
} 
4.1. The proxy for expected future income. The proxy for expected future income is expected future subjective well-being (see Appendix B for wording). This sub-section addresses two concerns that one should have about this measure. The first is whether or not subjective well-being is correlated with income. The second is whether or not the measure actually distinguishes between current and future circumstances.

It has already been established that income has a highly significant, positive effect on subjective well-being (Blanchflower and Oswald (2004); Frey and Stutzer (2002); Easterlin (2003)). In addition, general satisfaction with life is more strongly associated with levels of financial satisfaction than with satisfaction in other areas of life, including job satisfaction, housing satisfaction, health satisfaction, leisure satisfaction, and satisfaction with one's environment (Van Praag et al. (2003)).

In the Gallup data used for this paper, the correlation between current income and current subjective well-being is $0.240(\mathrm{~N}=4401$, significant at the one-percent level). To put this in perspective, the correlation between current income and the combined measure of opposition to redistribution is only $0.126(\mathrm{~N}=3409)$.

To test whether the proxy distinguishes between the present and the future, I employ additional data from the National Survey of Midlife Development in the U.S. 1995-1996 (MIDUS), a national sample of 4242 individuals from the ages of 25 to 74 years. The MIDUS survey contains questions on current and expected future 
subjective financial standing, unemployment status, employment leave for sickness or disability, and subjective well-being (See Table A2 for exact wording and selected summary statistics). The MIDUS and Gallup measures of subjective well-being are very similar to each other.

Table 2 predicts current subjective well being with current and expected future subjective financial standing, unemployment status, and employment leave for sickness or disability - controlling for age and age squared. For each measure, current circumstances have much larger effects (in absolute value) than expected future circumstances. For example, current unemployment is associated with a 0.718 standard deviation decrease in current subjective well-being (significant at the one-percent level). In contrast, expected future unemployment is associated with only a 0.276 standard deviation decrease in current subjective well-being (significant only at the ten-percent level).

Table 3 presents regressions predicting expected future subjective well-being with the three measures of current and expected future circumstances, controlling for age and age squared. In all three cases, expected future circumstances have much larger effects (in magnitude) on expected future subjective well-being than current circumstances.

Thus, expected future subjective well-being is a good proxy for expected future financial security. The contemporaneous association between financial security and 
subjective well-being is strong and the measures clearly distinguish between evaluations of current circumstances and expected future circumstances. The strength of this association is even more striking when one compares it to the small effects of expected future subjective well-being on opposition to redistribution in Section 5.

An alternative to the proxy is to use estimated coefficients from panel data to predict future income in cross-sectional data, as Alesina and La Ferrara (2001) did. While no measure is perfect, one advantage of the proxy used in this paper is that it is a direct, individually reported measure of expectations about the future rather than objective expected future income based on data from people other than the respondent. In theory, what matters for redistributive demands is the individual's own subjective expectations of future income, not his objective expected future income.

\section{Results}

Table 4 presents ordinary least squares regressions predicting opposition to redistribution with the belief that there is plenty of opportunity to get ahead, current pre-tax annual household income, age, age squared, race, gender, marital status and household size. To demonstrate the robustness of the relationship, the table presents the estimates for two sub-samples: individuals with pre-tax household incomes below $\$ 30,000$ and those with household incomes of $\$ 30,000$ and above. In both subsamples, the belief that opportunity is prevalent has highly significant positive effects on opposition to redistribution. I have shown elsewhere in more detail that this asso- 
ciation is extremely robust and cannot be explained by missing measures of pecuniary interests in redistribution (Fong (2001)).

Table 5 presents three different equations predicting 1) the proxy for expected future income, 2) the belief that poverty is caused by lack of effort rather than bad luck, and 3) the belief that wealth is caused by strong effort rather than good luck. All three of the dependent variables in this table are standardized to have means of zero and standard deviations of one. The table shows that the belief in the prevalence of opportunity has a highly significant association with all three of the dependent variables of this table. Thus, so far, both the prospective mobility and fairness hypotheses appear plausible. Further analysis of these relationships is not the primary goal of this paper, however, so let us now turn to the effects of prospective mobility and beliefs about worthiness on demands for redistribution.

Table 6 presents ordinary least squares equations predicting opposition to redistribution with the proxy for expected future income (Model 1), beliefs that lack of effort rather than bad luck cause poverty (Model 2a), and beliefs that strong effort rather than good luck cause wealth (Model 2b). Each model controls for age, age squared, race, gender, marital status, household size and current income. The table presents these regressions for two sub-samples: those with annual household incomes below $\$ 30,000$ and those with incomes of $\$ 30,000$ or above. Columns 1 and 2 show that the proxy for expected future income has significant effects in both sub-samples 
- at the five-percent level among those with household incomes less than $\$ 30,000$ and the one-percent level among those with household incomes of $\$ 30,000$ or above. Columns 3 and 4 repeat the analyses shown in columns 1 and 2, but exclude the proxy for expected future income and include dummies for beliefs about the causes of poverty. The belief that laziness rather than bad luck causes poverty is significant at the one-percent level in both sub-samples. The belief that both laziness and bad luck rather than bad luck alone cause poverty is also significant at the one-percent level in both sub-samples. Columns 5 and 6 repeat the analysis a third time, excluding the dummies for beliefs about the causes of poverty and including dummies for beliefs about the causes of wealth. Again, the beliefs are significant at the one-percent level in both sub-samples.

An important point of Table 6 is that the measures produce statistically significant support for both the prospects of upward mobility and fairness hypotheses, and that these effects appear fairly robust (e.g., to dividing the sample into sub-samples by income) in qualitative sensitivity analysis. However, what this qualitative approach fails to reveal is that the apparent support for the prospects of upward mobility is actually very sensitive to measurement error in current income, while the apparent support for the fairness model is not. The following sub-section shows this with the quantitative sensitivity analysis. 
5.1. Quantitative sensitivity analysis. In Table 6 , only $x_{k-1}$ (i.e., expected future in come in Model 1 and beliefs in Models 2a and 2b), race, gender and current income have robust effects. This section quantitatively examines the sensitivity of the first three of these variables to measurement error in the fourth.

Bounds on the coefficients. Tables 7-9 re-estimate Models 1, 2a and 2b, respectively, using the whole sample. In Tables 8 and 9, instead of using dummy variables for beliefs I use the single combined measure of beliefs about the causes of poverty and the single combined measure of beliefs about the causes of wealth that are described in Section 4.

Columns 1 and 2 of Tables 7-9 show the bounds on $\alpha_{K-1}^{*}$ for each model. One set of bounds comes from the direct regression of opposition to redistribution on the independent variables. These bounds are presented in column 1 . The second set of bounds are the normalized coefficients calculated by first estimating the reverse regressions of current income on the remaining independent variables and opposition to redistribution, and then solving for opposition to redistribution on the left hand side. These bounds are presented in column 2 .

In Models 1 and 2b, the bounds on $\alpha_{K-1}^{*}$ differ in sign. In Model 2a, the bounds have the same sign. In all three models, the estimated coefficients on $x_{k-1}$ in the direct regression were positive and significant. In Models 1 and $2 \mathrm{~b}$, without further information, the coefficient on $x_{k-1}$ is meaningless in the sense that measurement 
error in current income may be creating biases that generate a positive coefficient on $x_{k-1}$ when its true effect may be zero or even of the opposite sign. In contrast, in Model 2a, the bounds show that the estimated coefficient on $x_{k-1}$ has the correct sign, no matter how poorly current income is measured.

Robustness of the coefficients. In Tables 7-9, column 4 presents the robustness statistics for the coefficients whose bounds had opposite signs. Table 7 presents the results for Model 1. Column 4 shows that if $66 \%$ of the variance in the measure of current income is due to measurement error, then the coefficient is meaningless in the sense that the true effect is zero. The robustness of other regressors $x_{i} \neq x_{K-1}$ can be calculated by substituting $\alpha_{i}$ and $\gamma_{i}$ for $\alpha_{K-1}$ and $\gamma_{K-1}$ in Equation 10. Doing this for race and gender shows that their estimated coefficients are similar to each other in magnitude. Their robustness statistics are also similar: $79 \%$ and $81 \%$ for race and gender, respectively.

Column 4 of Table 8 presents the robustness results for Model 2a. The robustness of beliefs is not pertinent here because the bounds on this variable had the same sign. In Model 2a, the magnitudes and robustness of the effects of race and gender are, again, similar to each other. Table 9 presents results for Model 2b. This table shows that $82 \%$ of the variance in current income must be due to measurement error to explain the estimated coefficient on beliefs if the true coefficient is zero. Here, again, the magnitudes and robustness of the effects of race and gender are roughly 
the same.

I estimated models using other specifications of the proxy for expected future income and beliefs about the causes of income, still assuming that current income is the only poorly measured variable (unreported). The results were essentially the same. For example, I estimated Model 1 representing the proxy for expected future income with quartile dummies, omitting the first quartile dummy. The estimated robustness statistics for the second, third, and fourth quartiles are $64 \%, 60 \%$, and $68 \%$, respectively. I also re-estimated the fairness models, representing the beliefs measures with a dummy variable for the belief that both luck and effort levels matter and a dummy variable for the belief that only effort levels matter (omitting the dummy for the belief that only luck matters). In Model $2 \mathrm{~b}$, the estimated robustness statistics for both included dummies is $82 \%$. In Model 2a, the robustness is even higher and for one of the beliefs coefficients, both bounds are positive. Thus, even with these alternative specifications, the prospective mobility model is the most sensitive to measurement error in current income.

Finally, let us ask: Is measurement error in current income potentially high enough to explain the entire estimated coefficient on expected future income in the prospective mobility model? Based on the robustness statistics presented in Table 7 $(66 \%)$, this could not be the case if we could explain more than $34 \%$ of the variation in current income with predictors of income that are not correlated with its measurement 
error. Regressing current income on age, age squared, household size, dummies for white, male, married and nine category dummies for household assets explains $38.9 \%$ percent of the variance in current income. We might interpret this equation as a rough indicator of the fraction of the variance in current income that cannot be due to error. Of course, it is not a perfect indicator, because the measure of assets may be correlated with measurement error in current income. Nonetheless, it seems plausible that all of the estimates coefficients in Models 1, 2a and $2 \mathrm{~b}$ at least have the correct sign.

Despite this, Tables 7-9 suggest that the prospective mobility model (Model 1) is much more sensitive to measurement error in current income than the fairness models (Models 2a and 2b). We can analyze this sensitivity further by calculating the robustness statistics for other values of $\alpha_{k-1}^{*}$ besides zero. Table 10 presents the robustness statistics for each of the three models when $\alpha_{k-1}^{*}=.5 \alpha_{k-1}$ and $\alpha_{k-1}^{*}=$ $.75 \alpha_{k-1}$. These robustness statistics tell us how much measurement error in current income it would take to explain the estimated coefficient if the true coefficient has only half or three-quarters the magnitude of the estimated coefficient.

Table 10 shows that Model 1 is very sensitive to measurement error in current income while Models $2 \mathrm{a}$ and $2 \mathrm{~b}$ are quite robust. If $53.7 \%$ of the variance in current income is due to measurement error, then the true coefficient on expected future income in Model 1 has only half the magnitude of the estimated coefficient. If just 
$38.9 \%$ of the variance in current income is due to measurement error, then the true coefficient on expected income has only three-quarters the magnitude of the estimated coefficient. Both of these levels of measurement error in current income are plausible, so Model 1 is quite sensitive.

In contrast, Models $2 \mathrm{a}$ and $2 \mathrm{~b}$ are very robust to measurement error in current income. In Model 2a, $85.6 \%$ of the variance in current income would have to be due to measurement error to explain the estimated coefficient if the true coefficient were half its size. Even if the true coefficient had three-quarters the magnitude of the estimated coefficient, it would still require $82.9 \%$ of the variance in current income to explain the estimated coefficient with measurement error bias. The robustness statistics in Model 2b are also quite high: $77.9 \%$ when the true coefficient has half the magnitude of the estimated coefficient, and $70.6 \%$ when the true coefficient has three quarters the magnitude of the estimated coefficient.

Why are the fairness models so robust while the prospects of upward mobility model is so sensitive? From Tables 7-9, it is clear that neither $\alpha_{K}$ nor $\widehat{\sigma}_{K}$ differ much across the three models. Instead, the difference in robustness across the models is driven by the ratio of $\gamma_{K-1}$ to $\alpha_{K-1}$ (see Equation 11). That is, the stronger the association between $x_{K-1}$ and current income relative to the association between $x_{K-1}$ and opposition to redistribution, the more sensitive $\alpha_{K-1}$ will be to measurement error in current income. In Model 1, the effect of the proxy for expected future income 
on current income in column 3 is 9.5 times larger than its effect on opposition to redistribution in column 1. In contrast, in Model 2a, the effect of the belief that lack of effort rather than bad luck causes poverty on current income in column 3 is $51 \%$ smaller than its effect in column 1 . The lower robustness of Model $2 \mathrm{~b}$ compared to Model 2a is due to the fact that $\gamma_{K-1}$ is higher in Model $2 \mathrm{~b}$ while $\alpha_{K-1}$ is roughly comparable. That is, the belief about the causes of wealth is more strongly associated with current income than the belief about the causes of poverty, while the estimated effects of these beliefs on opposition to redistribution are similar.

\section{Conclusion}

This paper has tested two major views about the relationship between beliefs about mobility and redistributive politics. The prospective mobility view assumes that actors are purely selfish. According to this view, individuals' expectations of upward mobility will decrease their demands for redistribution because of smaller expected net benefits from redistribution. The fairness view holds that people who believe that there are few constraints to upward mobility believe that the economy is a meritocracy and, therefore, that the pre-fiscal distribution of income is fair. Both of these views are important to research and policy because they offer explanations for why we do not witness more redistribution in democracies even though the majority would benefit from it.

The data show strong support for the fairness view. In contrast, there is no 
robust support for the prospective mobility view. This weak support is not due to measurement error in the proxy for expected future income (see Appendix A). Instead, the problems are that expected future income is correlated with current income and the effect of the expected future income is small. These two problems make the estimated effect of expected future income sensitive to measurement error in current income.

Why does the prospective mobility view seem so intuitive if the empirical support for it is so weak? One possible reason is that both views draw intuition from the same empirical regularity, namely that those who believe there is plenty of opportunity are more opposed to redistribution. Loyalty to the assumption of purely self-interested actors may predispose people to interpret this empirical regularity as evidence of the prospective mobility view. However, the empirical regularity may be caused primarily by fairness concerns.

Self-regarding motives do matter, as evidenced by the significant effects of current income on opposition to redistribution. However, pecuniary self-interest simply is not strong enough for an individual to oppose redistribution just because she may suffer financial losses from it in the future. Instead, the evidence supports the idea that preferences for redistribution are based largely on judgments about whether or not the poor deserve to be poor and the rich deserve to be rich. 


\section{A. Appendix: Quantitative Sensitivity analysis with two poorly}

\section{MEASURED REGRESSORS}

When all regressors are measured with error, one can check for bounds by estimating the main regression and a reverse regression for each regressor. If the coefficients from the main regression and the normalized coefficients from the reverse regressions have the same sign, then the true coefficients are bounded by the convex hull of these regressions (Klepper and Leamer (1984)). Unlike the case of a singly poorly measured regressor, in this case, if any of the normalized coefficients from the reverse regressions have the opposite sign of the coefficients from the direct regression, then without additional information, all of the coefficients are unbounded and none of them can be identified. The case with two poorly measured regressors is a restricted case of this. One can calculate the bounds on the coefficients with the direct regression and a reverse regression predicting each poorly measured regressor. If the coefficients on the poorly measured variables change signs when they are calculated from the reverse regressions, then the coefficients are unbounded and cannot be identified, unless we have further information.

Regarding Model 1, we already know from Table 7 that the estimated coefficients on current income and expected future income from the direct regressions and the normalized coefficients from the indirect regression predicting current income differ in sign. Thus, these coefficients are unbounded if we assume that both regressors 
are measured with error. Similarly, regarding Model $2 \mathrm{~b}$, we know from Table 9 that the coefficients on current income and the belief that wealth is caused by strong effort are unbounded if we allow more than one regressor to be measured with error. In contrast, regarding Model 2a, Table 8 shows that the estimated coefficients on the beliefs variable and on current income have the same sign in both the direct regression and when calculated from the indirect regression predicting current income. Furthermore, the normalized coefficients on beliefs and current income calculated from the indirect regression predicting beliefs have the same sign as they do in Table 8 (unreported). Thus, in Model 2a, the true coefficients on current income and on beliefs are bounded.

We can analyze the unbounded models further with additional prior information about measurement error. The analysis below does this using diagnostics described in Klepper et. al. (1993). Let us begin with Model 1. Consider the main regression where opposition to redistribution is regressed on all of the regressors. Let $R^{* 2}$ be the value that the $R^{2}$ of this main regression would have if all of the measurement error in the regressors were removed. One can compute the maximal value that $R^{* 2}$ can take on and still bound the coefficients. Let us call this maximal value $M$. If $R^{* 2}<M$, then the true coefficients in the model can be bounded. In Model 1, when both current income and prospective mobility may be measured with error, $M=0.1276$. Recall from column 1 of Table 7 that the $R^{2}$ of the main regression is 0.08 . Is it 
plausible that after removing all measurement error from the regressors, $R^{* 2}$ would be less than $M$ ? We expect many other factors besides the included variables to help explain demands for redistribution, including racial group loyalty, fairness concerns, social identity, and values, beliefs and loyalties that are culturally inherited from parents and others. As it turns out, without accounting for these factors, it appears unlikely that improving measurement error in the included variables could increase the explanatory power to $M=0.1276$. As a rough indicator, I added a large number of variables to the model that might help capture the effects of current and expected future income. These additional measures include subjective class, the extent to which the respondent worries about paying bills, dummies for whether or not the respondent has enough money to pay for medical bills, clothes and food, current subjective well-being, four occupation dummies (manager, service worker, laborer and administrative support worker), nine dummies for household assets, two employment status dummies, seven education dummies, and dummies for urban and suburban respondents (as opposed to rural respondents) and four additional marital status dummies. Adding all of these measures to Model 1 increased its $R^{2}$ to only 0.0983 .

We can take this a step further and calculate necessary conditions for $R^{* 2}$ to be less than $M$. First, according to these diagnostics, the variance of the measurement error in current income can be no more than $66.4 \%$ of the variance in current income. 
Recall from Section 5.1 that this necessary condition seems reasonable. Second, the measurement error in the proxy for expected future income can be no more than $84.18 \%$ of the variance in this measure. The second necessary condition seems reasonable based on the analysis presented in Section 4.1.

Thus, it is reasonable to believe that both necessary conditions are satisfied and that $R^{* 2}<0.1276$. We can thus calculate bounds on the coefficients of Model 1 . Table A1 presents the bounds in Model 1 that result from assuming $R^{* 2}=0.127$.

The same procedure applied to Model $2 \mathrm{~b}$ again shows reasonable conditions for imposing restrictions and calculating bounds. In Model $2 \mathrm{~b}, M=.3042$ while the $R^{2}$ of the main regression is only .1329. Based on unreported analysis in which I add additional measures to the model to capture current income and beliefs about the causes of wealth more fully, it seems implausible that the $R^{2}$ of the main regression could increase all the way to .3042 just by eliminating measurement error in current income and the belief that strong effort causes wealth. Table A1 presents the bounds in Model $2 \mathrm{~b}$ that result from assuming $R^{* 2}=.304$. Finally, recall that no additional information is needed to bound the coefficients in Model 2a, because they are already bounded without it. Table A1 presents the bounds for Model 2a as well.

One way to use these bounds to interpret the reliability of the models is to compare the bounds on current income to the bounds on $x_{K-1}$, keeping in mind that in each model the set of true coefficients is bounded by the convex hull of these three sets of 
bounds. Note that the estimated coefficients on income from the direct regression do not differ much across the models. We might expect this to be the case for the true coefficients on income as well. There is no reason to expect the true effect of income to differ dramatically across the models. Next, note that if the true coefficient on income were to increase to just 0.138 (the second bound in Model 1), then the true effect of expected future income would fall almost to zero. In contrast, in Models $2 \mathrm{a}$ and $2 \mathrm{~b}$, if the true coefficients on beliefs were to fall to their lowest possible level, the true coefficient on income would have to be substantially larger (1.865 in Model 2a and 0.494 in Model 2b). 


\section{B. Appendix: Summary Statistics And question Wording}

\section{Questions from Gallup Social Audit}

\begin{tabular}{clc} 
Income: Total annual household income before taxes. \\
\hline Income categories & Category medians & $\%$ of sample \\
\hline less than $\$ 10,000$ & $\$ 7,500$ & $5.86 \%$ \\
$\$ 10,000-\$ 14,999$ & $\$ 12,500$ & $5.49 \%$ \\
$\$ 15,000-\$ 19,999$ & $\$ 17,500$ & $7.20 \%$ \\
$\$ 20,000-\$ 29,999$ & $\$ 25,000$ & $16.12 \%$ \\
$\$ 30,000-\$ 49,999$ & $\$ 40,000$ & $28.20 \%$ \\
$\$ 50,000-\$ 74,999$ & $\$ 60,000$ & $19.27 \%$ \\
$\$ 75,00-\$ 99,999$ & $\$ 85,000$ & $9.30 \%$ \\
$\$ 100,000-\$ 149,999$ & $\$ 125,000$ & $5.21 \%$ \\
$\$ 150,000$ or more & $\$ 200,000$ & $3.35 \%$
\end{tabular}

Income categories are from the Gallup data.

Category medians are from CPS data.

Beliefs in opportunity: "Some people say there's not much opportunity in America today - that the average person doesn't have much chance to really get ahead. Others say there's plenty of opportunity and anyone who works hard can go as far as they want. Which one comes closer to the way you feel about this?

Not much opportunity: $16.64 \%$ 
Plenty of opportunity: $83.36 \%$

$\mathrm{N}=4898$

Taxrich: People feel differently about how far a government should go. Here is a phrase which some people believe in and some don't. Do you think our government should or should not redistribute wealth by heavy taxes on the rich?

Should: $44.99 \%$

Should Not: $55.01 \%$

$\mathrm{N}=4832$

Govpoor: Some people feel that the government in Washington, DC should make every possible effort to improve the social and economic position of the poor. Others feel that the government should not make any special effort to help the poor, because they should help themselves. How do you feel about this?

Government should help the poor: $69.39 \%$

The poor should help themselves: $30.61 \%$

$$
\mathrm{N}=4704
$$

Acceptance of inequality: Do you think that the fact that some people in the United States are rich and others are poor?

Represents a problem that needs to be fixed: $52.53 \%$

Is an acceptable part of our economic system: $47.47 \%$ 
$\mathrm{N}=4858$

Whypoor? Just your opinion, which is more often to blame if a person is poor lack of effort on his or her part, or circumstances beyond his or her control?

Lack of effort: $43.58 \%$

Circumstances beyond his/her control: $41.90 \%$

Both: $14.52 \%$

$\mathrm{N}=4869$

Whyrich? Just your opinion, which is more often to blame if a person is rich -strong effort to succeed on his or her part, or luck or circumstances beyond his or her control?

Strong effort: $56.05 \%$

Luck or circumstances beyond his/her control: $32.11 \%$

Both: $11.84 \%$

$\mathrm{N}=4833$

Current subjective well-being: "Think of a picture of a ladder. Suppose we say that the top of the ladder represents the best possible life for you, and the bottom represents the worst possible life for you. If the top step is "10" and the bottom step is "0", on which step of the ladder do you feel you personally stand at the present time?" 
Mean $=7.11$, s.d. $=1.76, \mathrm{~N}=4977$

Expected future subjective well-being: "Just your best guess, on which step do you think you will stand in the future, say about five years from now?"

Mean $=8.23$, s.d. $=1.84, \mathrm{~N}=4797$

\section{Questions from the MIDUS survey}

Current subjective well-being: "How would you rate your life overall these days?"

Mean $=7.64$, s.d. $=1.67, \mathrm{~N}=3620$

Expected future subjective well-being: "Looking ahead ten years into the future, what do you expect your life overall will be like at that time?"

Scored from zero (worst) to ten (best).

Mean $=8.24$, s.d. $=1.71, \mathrm{~N}=3611$

Current Subjective financial standing: "How would you rate your financial situation these days?"

Scored from zero (worst) to ten (best).

Mean $=5.98$, s.d. $=2.23, \mathrm{~N}=3623$

Expected future subjective financial standing:"Looking ahead ten years into the future, what do you expect your financial situation will be like at that time?" Scored from zero (worst) to ten (best). Mean $=$, s.d. $=$ Mean $=7.31$, s.d. $=2.06, \mathrm{~N}=3636$ 
Current unemployment: "Are you now unemployed and looking for work?"

no: $95.29 \%$

yes: $4.71 \%$

$\mathrm{N}=3377$

Expected future unemployment: "10 years from now, do you expect to be unemployed and looking for work?"

no: $97.83 \%$

yes: $2.17 \%$

$\mathrm{N}=3357$

Current sickness/disability leave: "Are you now on extended sick leave or disability?"

no: $95.57 \%$

yes: $4.43 \%$

$\mathrm{N}=3387$

Expected future sickness/disability leave: "10 years from now do you expect to be on extended sick leave or disability?"

no: 96.53

yes: 3.47

$\mathrm{N}=3346$ 


\section{REFERENCES}

Alesina, A. and G.-M. Angeletos (2005). Fairness and redistribution: US versus Europe. American Economic Review 95(4), 913-935.

Alesina, A., E. Glaeser, and B. Sacerdote (2001). Why doesn't the United States have a European-style welfare state? Brookings Papers on Economic Activity 2, $187-278$.

Alesina, A. and E. La Ferrara (2005). Preferences for redistribution in the land of opportunities. Journal of Public Economics 89(5-6), 897-931.

Benabou, R. and E. Ok (2001). Social mobility and the demand for redistribution: The POUM hypothesis. Quarterly Journal of Economics CXVI, 447-487.

Benabou, R. and J. Tirole (forthcoming). Belief in a just world and redistributive politics. Quarterly Journal of Economics.

Blanchflower, D. G. and A. J. Oswald (2004). Well-being over time in Britain and the U.S.A. Journal of Public Economics 88, 1359-1386.

Bolton, G. and A. Ockenfels (2000). ERC-a theory of equity, reciprocity, and competition. American Economic Review 90, 166-93.

Charness, G. and M. Rabin (2002). Understanding social preferences with simple tests. Quarterly Journal of Economics CXVII, 817-869. 
Chow, G. C. (1957). Demand for Automobiles in the United States. Amsterdam: North-Holland.

Dufwenberg, M. and G. Kirchsteiger (1999). A theory of sequential reciprocity. Games and Economic Behavior forthcoming.

Easterlin, R. A. (2003). Explaining happiness. National Academy of Sciences 100, $11176-11183$.

Eckel, C. and P. Grossman (1996). Altruism in anonymous dictator games. Games and Economic Behavior 16, 181-91.

Falk, A. and U. Fischbacher (1998). A theory of reciprocity. University of Zurich Working Paper.

Fehr, E. and K. Schmidt (1999). A theory of fairness, competition and cooperation. Quarterly Journal of Economics 114, 817-868.

Fong, C. M. (2001). Social preferences, self-interest, and the demand for redistribution. Journal of Public Economics 82(2), 225.

Fong, C. M. (2004). Empathic responsiveness: Evidence from a randomized experiment on giving to welfare recipients.

Fong, C. M., S. Bowles, and H. Gintis (forthcoming). Reciprocity and the welfare 
state. In S.-C. Kolm and J. M. Ythier (Eds.), Handbook on the Economics of Giving, Reciprocity, and Altruism. Amsterdam: North-Holland/Elsevier.

Frey, B. and A. Stutzer (2002). What can economists learn from happiness research? Journal of Economic Literature 40(2), 402-435.

Gallup Organization (1998). Haves and have-nots: Perceptions of fairness and opportunity.

Gilens, M. (1999). Why Americans Hate Welfare. Chicago: University of Chicago Press.

Graham, C. and S. Pettinato (2002). Happiness and Hardship (first ed.). Washington, D.C.: Brookings Institution Press.

Heclo, H. (1986). The political foundations of antipoverty policy. In S. H. Danziger and D. H. Weinberger (Eds.), Fighting Poverty, pp. 312-40. Cambridge: Harvard University Press.

Hirschman, A. (1973). The changing tolerance for income inequality in the course of economic development, with a mathematical appendix by Michael Rothschild. Quarterly Journal of Economics 87, 544-566.

Klepper, S., M. Kamlet, and R. Frank (1993). Regressor diagnostics for the errors- 
in-variables model - an application to the health effects of pollution. Journal of Environmental Economics and Management 24, 190-211.

Klepper, S. and E. E. Leamer (1984). Consistent sets of estimates for regressions with errors in all variables. Econometrica 52(January), 163-184.

Kluegel, J. R. and E. R. Smith (1986). Beliefs About Inequality: Americans Views of What Is and What Ought to Be. New York: Aldine de Gruyter.

Levine, D. (1998). Modeling altruism and spitefulness in experiments. Review of Economic Dynamics 1, 593-622.

Luttmer, E. (2001). Group loyalty and the taste for redistribution. Journal of Political Economy 109(3), 500-28.

Meltzer, A. and S. Richard (1981). A rational theory of the size of government. Journal of Political Economy 89(5), 814-927.

Putterman, L. (1997). Why have the rabble not redistributed the wealth? on the stability of democracy and unequal property. In J. E. Roemer (Ed.), Property Relations, Incentives and Welfare: Proceedings of a Conference Held in Barcelona, Spain, by the International Economic Association, Chapter 13, pp. 359-389. New York: St. Martin's Press. 
Rabin, M. (1993). Incorporating fairness into game theory and economics. American Economic Review 83(5), 1281-92.

Ravallion, M. and M. Lokshin (2000). Who wants to redistribute? the tunnel effect in 1990s Russia. Journal of Public Economics 76, 87-104.

Roberts, K. (1977). Voting over income tax schedules. Journal of Public Economics 8, $329-340$.

Roemer, J. E. (1998, December). Why the poor do not expropriate the rich: An old argument in new garb. Journal of Public Economics 70(3), 399-424.

Rotemberg, J. (2004). Minimally acceptable altruism and the ultimatum game. Mimeo.

Van Praag, B., P. Frijters, and A. Ferrer-i-Carbonell (2003). The anatomy of subjective well-being. Journal of Economic Behavior and Organization 51, 29-49.

Williamson, J. B. (1974). Beliefs about the motivation of the poor and attitudes toward poverty policy. Social Problems 21(5), 734-747. 
Table 1. Definitions of selected variables and statistics used to produce sensitivity estimates.

\begin{tabular}{ll}
\hline \hline$x_{K}$ & Current income \\
$x_{K-1}$ & In Model 1: Proxy for expected future income \\
& In Model 2a: Belief that lack of effort rather than bad luck causes poverty \\
& In Model 2b: Belief that strong effort rather than good luck causes wealth \\
$\alpha_{K}$ & Coefficient on $x_{K}$ in main regression \\
$\alpha_{K-1}$ & Coefficient on $x_{K-1}$ in main regression \\
$\hat{\sigma}_{K}$ & Residual var. of auxiliary reg. of $x_{K}$ on other regressors \\
$\gamma_{K-1}$ & Coefficient on $x_{K-1}$ in auxiliary regression of $x_{K}$ on other regressors \\
$V\left(x_{K}\right)$ & Sample variance of $x_{K}$ \\
\hline
\end{tabular}


Table 2. Ordinary least squares regressions predicting current subjective wellbeing (in std. dev. units) using MIDUS data.

\begin{tabular}{|c|c|c|c|}
\hline & (1) & (2) & (3) \\
\hline $\begin{array}{l}\text { Subjective financial standing (std. } \\
\text { dev. units) }\end{array}$ & $\begin{array}{l}0.426 * * * \\
(0.022)\end{array}$ & & \\
\hline $\begin{array}{l}\text { Expected subj. fin. standing in } 10 \\
\text { yrs. (std. dev. units) }\end{array}$ & $\begin{array}{l}0.166^{* * *} \\
(0.023)\end{array}$ & & \\
\hline Unemployed (dummy) & & $\begin{array}{l}-0.718 * * * \\
(0.108)\end{array}$ & \\
\hline Expects future unemp. (dummy) & & $\begin{array}{l}-0.276^{*} \\
(0.153)\end{array}$ & \\
\hline Sick or disabled (dummy) & & & $\begin{array}{l}-0.875^{* * *} \\
(0.164)\end{array}$ \\
\hline $\begin{array}{l}\text { Expects future sickness or } \\
\text { disability (dummy) }\end{array}$ & & & $\begin{array}{l}-0.233 \\
(0.171)\end{array}$ \\
\hline Age & $\begin{array}{l}-0.033 * * * \\
(0.008)\end{array}$ & $\begin{array}{l}-0.018 * * \\
(0.009)\end{array}$ & $\begin{array}{l}0.012 * * * \\
(0.001)\end{array}$ \\
\hline Age2 & $\begin{array}{l}0.000 * * * \\
(0.000)\end{array}$ & $\begin{array}{l}0.000 * * * \\
(0.000)\end{array}$ & \\
\hline Observations & 3543 & 3269 & 3264 \\
\hline R-squared & 0.29 & 0.05 & 0.06 \\
\hline
\end{tabular}

Numbers shown are ordinary least squares coefficients (rob. s.e. in parentheses). $*, * *$, and $* * *$ indicate significance at the ten-, five- and one-percent levels, respectively. Regressions also income a constant. 
Table 3. Ordinary least squares regressions predicting expected future subjective well-being (in std. dev. units) using MIDUS data.
(1)
(2)

(3)

Subjective financial standing (std.

dev. units)

$0.046^{* *}$

Expected subj. fin. standing in 10

(0.018)

yrs. (std. dev. units)

$0.504 * * *$

(0.025)

Unemployed (dummy)

$-0.142 *$

(0.083)

Expects future unemp. (dummy)

$-0.478 * * *$

(0.152)

Sick or disabled (dummy)

$-0.342 * *$

(0.171)

Expects future sickness or

$-0.879 * * *$

disability (dummy)

(0.200)

Age

$\begin{array}{lll}-0.002 & -0.002 & 0.005 \\ (0.008) & (0.010) & (0.010)\end{array}$

$\mathrm{Age}^{2}$

$-0.000 \quad-0.000$

$-0.000 * *$

$(0.000)$

$(0.000)$

$(0.000)$

\begin{tabular}{llll}
\hline Observations & 3536 & 3262 & 3256 \\
R-squared & 0.31 & 0.06 & 0.10 \\
\hline
\end{tabular}

Numbers shown are ordinary least squares coefficients (rob. s.e. in parentheses). $*$, **, and *** indicate significance at the ten-, five- and one-percent levels, respectively. Regressions also income a constant. 
Table 4. OLS regressions predicting opposition to redistribution with beliefs in opportunity.

\begin{tabular}{|c|c|c|}
\hline & \multicolumn{2}{|c|}{ Sub-sample } \\
\hline & (1) & $(2)$ \\
\hline & Income $<\$ 30,000$ & Income $\geq \$ 30,000$ \\
\hline Belief in opportunity & $\begin{array}{l}0.509 * * * \\
(0.052)\end{array}$ & $\begin{array}{l}0.737 * * * \\
(0.049)\end{array}$ \\
\hline White & $\begin{array}{l}0.243 * * * \\
(0.054)\end{array}$ & $\begin{array}{l}0.330 * * * \\
(0.048)\end{array}$ \\
\hline Male & $\begin{array}{l}0.295 * * * \\
(0.050)\end{array}$ & $\begin{array}{l}0.258 * * * \\
(0.037)\end{array}$ \\
\hline Income/10,000 & $\begin{array}{l}0.098 * * * \\
(0.037)\end{array}$ & $\begin{array}{l}0.022 * * * \\
(0.004)\end{array}$ \\
\hline Age & $\begin{array}{l}-0.013^{*} \\
(0.007)\end{array}$ & $\begin{array}{l}-0.002 \\
(0.007)\end{array}$ \\
\hline Age squared & $\begin{array}{l}0.000 * * \\
(0.000)\end{array}$ & $\begin{array}{l}0.000 \\
(0.000)\end{array}$ \\
\hline Married & $\begin{array}{l}0.032 \\
(0.056)\end{array}$ & $\begin{array}{l}0.050 \\
(0.044)\end{array}$ \\
\hline Household size & $\begin{array}{l}-0.013 \\
(0.016)\end{array}$ & $\begin{array}{l}-0.012 \\
(0.015)\end{array}$ \\
\hline Observations & 1374 & 2666 \\
\hline R-squared & 0.12 & 0.12 \\
\hline
\end{tabular}

Numbers shown are OLS coefficients (rob. s.e. in parenthesis). *,**, and *** indicate significance at the ten-, five- and one-percent levels, respectively. Regressions also include a constant. 
Table 5. OLS regressions predicting (1) proxy for expected future income, (2) beliefs that lack of effort causes poverty, and (3) beliefs that strong effort causes wealth.

\begin{tabular}{|c|c|c|c|}
\hline & \multicolumn{3}{|c|}{ Dependent Variable } \\
\hline & (1) & (2) & (3) \\
\hline & $\begin{array}{l}\text { Expected future well- } \\
\text { being (std. dev. units) }\end{array}$ & $\begin{array}{l}\text { Poverty caused by lack } \\
\text { of effort (std. dev. units) }\end{array}$ & $\begin{array}{c}\text { Wealth caused by strong } \\
\text { effort (std. dev. units) }\end{array}$ \\
\hline $\begin{array}{l}\text { Belief in } \\
\text { opportunity }\end{array}$ & $\begin{array}{l}0.322 * * * \\
(0.045)\end{array}$ & $\begin{array}{l}0.644 * * * \\
(0.036)\end{array}$ & $\begin{array}{l}0.590 * * * \\
(0.042)\end{array}$ \\
\hline White & $\begin{array}{l}-0.163 * * * \\
(0.039)\end{array}$ & $\begin{array}{l}0.161 * * * \\
(0.039)\end{array}$ & $\begin{array}{l}0.129 * * * \\
(0.041)\end{array}$ \\
\hline Male & $\begin{array}{l}-0.206 * * * \\
(0.029)\end{array}$ & $\begin{array}{l}0.226 * * * \\
(0.030)\end{array}$ & $\begin{array}{l}-0.027 \\
(0.030)\end{array}$ \\
\hline Income/10,000 & $\begin{array}{l}0.033 * * * \\
(0.003)\end{array}$ & $\begin{array}{l}0.001 \\
(0.004)\end{array}$ & $\begin{array}{l}0.029 * * * \\
(0.004)\end{array}$ \\
\hline Age & $\begin{array}{l}-0.021 * * * \\
(0.006)\end{array}$ & $\begin{array}{l}-0.012 * * \\
(0.005)\end{array}$ & $\begin{array}{l}-0.006 \\
(0.005)\end{array}$ \\
\hline Age squared & $\begin{array}{l}0.000 \\
(0.000)\end{array}$ & $\begin{array}{l}0.000 \\
(0.000)\end{array}$ & $\begin{array}{l}0.000 \\
(0.000)\end{array}$ \\
\hline Married & $\begin{array}{l}0.090 * * * \\
(0.034)\end{array}$ & $\begin{array}{l}0.100 * * * \\
(0.034)\end{array}$ & $\begin{array}{l}0.007 \\
(0.035)\end{array}$ \\
\hline Household size & $\begin{array}{l}0.004 \\
(0.011)\end{array}$ & $\begin{array}{l}-0.008 \\
(0.012)\end{array}$ & $\begin{array}{l}0.001 \\
(0.012)\end{array}$ \\
\hline Observations & 4276 & 4326 & 4310 \\
\hline R-squared & 0.11 & 0.09 & 0.07 \\
\hline
\end{tabular}

Numbers shown are OLS coefficients (rob. s.e. in parenthesis). *,**, and $* * *$ indicate significance at the ten-, five- and one-percent levels, respectively. Regressions also include a constant. 
Table 6. OLS regressions predicting opposition to redistribution with the proxy for expected future income and beliefs about causes of income.

\begin{tabular}{|c|c|c|c|c|c|c|}
\hline & \multicolumn{6}{|c|}{ Sub-sample } \\
\hline & (1) & (2) & (3) & (4) & (5) & (6) \\
\hline & $\mathrm{Y}<\$ 30 \mathrm{k}$ & $Y \geq \$ 30 k$ & $\mathrm{Y}<\$ 30 \mathrm{k}$ & $Y \geq \$ 30 k$ & $\mathrm{Y}<\$ 30 \mathrm{k}$ & $Y \geq \$ 30 k$ \\
\hline $\begin{array}{l}\text { Proxy for expected future } \\
\text { income (std. dev. units) }\end{array}$ & $\begin{array}{l}0.044 * * \\
(0.022)\end{array}$ & $\begin{array}{l}0.074 * * * \\
(0.025)\end{array}$ & & & & \\
\hline $\begin{array}{l}\text { Both bad luck and lack of } \\
\text { effort cause poverty } \\
\text { (dummy) }\end{array}$ & & & $\begin{array}{l}0.209 * * * \\
(0.078)\end{array}$ & $\begin{array}{l}0.441 * * * \\
(0.058)\end{array}$ & & \\
\hline $\begin{array}{l}\text { Lack of effort causes } \\
\text { poverty (dummy) }\end{array}$ & & & $\begin{array}{l}0.467 * * * \\
(0.053)\end{array}$ & $\begin{array}{l}0.677 * * * \\
(0.039)\end{array}$ & & \\
\hline $\begin{array}{l}\text { Both good luck and } \\
\text { strong effort cause } \\
\text { wealth (dummy) }\end{array}$ & & & & & $\begin{array}{l}0.247 * * * \\
(0.090)\end{array}$ & $\begin{array}{l}0.312 * * * \\
(0.068)\end{array}$ \\
\hline $\begin{array}{l}\text { Strong effort causes } \\
\text { wealth (dummy) }\end{array}$ & & & & & $\begin{array}{l}0.417 * * * \\
(0.052)\end{array}$ & $\begin{array}{l}0.573 * * * \\
(0.041)\end{array}$ \\
\hline White & $\begin{array}{l}0.253 * * * \\
(0.056)\end{array}$ & $\begin{array}{l}0.350 * * * \\
(0.050)\end{array}$ & $\begin{array}{l}0.225^{* * *} \\
(0.054)\end{array}$ & $\begin{array}{l}0.278 * * * \\
(0.048)\end{array}$ & $\begin{array}{l}0.229 * * * \\
(0.055)\end{array}$ & $\begin{array}{l}0.303 * * * \\
(0.049)\end{array}$ \\
\hline Male & $\begin{array}{l}0.314 * * * \\
(0.053)\end{array}$ & $\begin{array}{l}0.295 * * * \\
(0.039)\end{array}$ & $\begin{array}{l}0.234 * * * \\
(0.051)\end{array}$ & $\begin{array}{l}0.211 * * * \\
(0.037)\end{array}$ & $\begin{array}{l}0.299 * * * \\
(0.051)\end{array}$ & $\begin{array}{l}0.288 * * * \\
(0.037)\end{array}$ \\
\hline Income/10,000 & $\begin{array}{l}0.129 * * * \\
(0.039)\end{array}$ & $\begin{array}{l}0.024 * * * \\
(0.005)\end{array}$ & $\begin{array}{l}0.114 * * * \\
(0.037)\end{array}$ & $\begin{array}{l}0.027 * * * \\
(0.004)\end{array}$ & $\begin{array}{l}0.114 * * * \\
(0.038)\end{array}$ & $\begin{array}{l}0.019 * * * \\
(0.005)\end{array}$ \\
\hline Age & $\begin{array}{l}-0.016^{* *} \\
(0.008)\end{array}$ & $\begin{array}{l}-0.005 \\
(0.007)\end{array}$ & $\begin{array}{l}-0.013^{*} \\
(0.008)\end{array}$ & $\begin{array}{l}-0.001 \\
(0.007)\end{array}$ & $\begin{array}{l}-0.011 \\
(0.008)\end{array}$ & $\begin{array}{l}-0.004 \\
(0.007)\end{array}$ \\
\hline Age squared & $\begin{array}{l}0.000 * * * \\
(0.000)\end{array}$ & $\begin{array}{l}0.000 \\
(0.000)\end{array}$ & $\begin{array}{l}0.000 * * \\
(0.000)\end{array}$ & $\begin{array}{l}0.000 \\
(0.000)\end{array}$ & $\begin{array}{l}0.000 * \\
(0.000)\end{array}$ & $\begin{array}{l}0.000 \\
(0.000)\end{array}$ \\
\hline Married & $\begin{array}{l}0.030 \\
(0.059)\end{array}$ & $\begin{array}{l}0.084^{*} \\
(0.046)\end{array}$ & $\begin{array}{l}0.044 \\
(0.056)\end{array}$ & $\begin{array}{l}0.034 \\
(0.043)\end{array}$ & $\begin{array}{l}0.041 \\
(0.057)\end{array}$ & $\begin{array}{l}0.075^{*} \\
(0.044)\end{array}$ \\
\hline Household size & $\begin{array}{l}-0.023 \\
(0.017)\end{array}$ & $\begin{array}{l}-0.023 \\
(0.015)\end{array}$ & $\begin{array}{l}-0.020 \\
(0.016)\end{array}$ & $\begin{array}{l}-0.015 \\
(0.015)\end{array}$ & $\begin{array}{l}-0.024 \\
(0.017)\end{array}$ & $\begin{array}{l}-0.017 \\
(0.015)\end{array}$ \\
\hline Observations & 1322 & 2649 & 1383 & 2638 & 1359 & 2640 \\
\hline R-squared & 0.07 & 0.06 & 0.12 & 0.15 & 0.11 & 0.12 \\
\hline
\end{tabular}

Numbers shown are OLS coefficients (rob. s.e. in parenthesis). *,**, and *** indicate significance at the ten-, five- and one-percent levels, respectively. Regressions also include a constant. 
Table 7. Quantitative sensitivity analysis of POUM model (Model 1). Auxiliary regression predicts current income. Main regression predicts opposition to redistribution.

\begin{tabular}{|c|c|c|c|c|}
\hline & $\begin{array}{c}(1) \\
\text { Direct } \\
\text { regression }\end{array}$ & $\begin{array}{l}\quad(2) \\
\text { Normalized } \\
\text { coefficients } \\
\quad \text { from } \\
\text { indirect reg. }\end{array}$ & $\begin{array}{l}\text { (3) } \\
\text { Auxiliary } \\
\text { regression }\end{array}$ & $\begin{array}{c}\text { (4) } \\
\text { Robustness }\end{array}$ \\
\hline $\begin{array}{l}\text { Proxy for expected future } \\
\text { income (std. dev. units) }\end{array}$ & $\begin{array}{l}0.062 * * * \\
(0.017)\end{array}$ & -1.140 & $\begin{array}{l}0.588 * * * \\
(0.054)\end{array}$ & $66.4 \%$ \\
\hline White & $\begin{array}{l}0.323 * * * \\
(0.037)\end{array}$ & -1.703 & $\begin{array}{l}0.990 * * * \\
(0.142)\end{array}$ & $79.0 \%$ \\
\hline Male & $\begin{array}{l}0.305 * * * \\
(0.031)\end{array}$ & -1.164 & $\begin{array}{l}0.718 * * * \\
(0.122)\end{array}$ & $80.7 \%$ \\
\hline Income/10k & $\begin{array}{l}0.033 * * * \\
(0.004)\end{array}$ & 2.078 & & \\
\hline Observations & 3971 & & 3971 & \\
\hline R-squared & 0.08 & & 0.13 & \\
\hline$\hat{\sigma}_{K}$ & & & 13.72 & \\
\hline
\end{tabular}

Column 1 presents OLS coefficients (robust s.e. in parentheses) for the model. These estimates provide one set of bounds on the true coefficients. Column 2 presents coefficients for the model calculated by first estimating the indirect regression of current income on the other independent variables and opposition to redistribution and then solving for opposition to redistribution as a function of the independent variables in the model. These estimates provide the second set of bounds on the true coefficients. Column 3 presents OLS coefficients (rob. s.e. in parentheses) from the auxiliary regression of current income on the other independent variables. *,**, and *** indicate significance at the ten-, five- and one-percent levels, respectively. Regressions also include a constant, age, age squared, household size and a dummy for being married. 
Table 8. Quantitative sensitivity analysis of fairness model (Model 2a). Auxiliary regression predicts current income. Main regression predicts opposition to redistribution.

\begin{tabular}{|c|c|c|c|c|}
\hline & $\begin{array}{c}\text { (1) } \\
\text { Main reg. }\end{array}$ & $\begin{array}{l}\quad(2) \\
\text { Normalized } \\
\text { coefficients } \\
\quad \text { from } \\
\text { indirect reg. }\end{array}$ & $\begin{array}{l}\text { (3) } \\
\text { Auxiliary } \\
\text { reg. }\end{array}$ & $\begin{array}{c}\text { (4) } \\
\text { Robustness }\end{array}$ \\
\hline $\begin{array}{l}\text { Belief that poverty is } \\
\text { caused by laziness }\end{array}$ & $\begin{array}{l}0.611 * * * \\
(0.032)\end{array}$ & 0.061 & $\begin{array}{l}0.300 * * \\
(0.128)\end{array}$ & $\begin{array}{c}\text { n.a. because } \\
\text { bounds have } \\
\text { same sign }\end{array}$ \\
\hline White & $\begin{array}{l}0.267 * * * \\
(0.036)\end{array}$ & -1.367 & $\begin{array}{l}0.892 * * * \\
(0.142)\end{array}$ & $79.5 \%$ \\
\hline Male & $\begin{array}{l}0.222 * * * \\
(0.030)\end{array}$ & -0.854 & $\begin{array}{l}0.587 * * * \\
(0.122)\end{array}$ & $81.2 \%$ \\
\hline Income/10,000 & $\begin{array}{l}0.033 * * * \\
(0.004)\end{array}$ & 1.865 & & \\
\hline Observations & 4021 & & 4021 & \\
\hline R-squared & 0.16 & & 0.12 & \\
\hline$\hat{\sigma}_{K}$ & & & 13.83 & \\
\hline
\end{tabular}

See notes to Table 7 . 
Table 9. Quantitative sensitivity analysis of fairness model (Model 2b). Auxiliary regression predicts current income. Main regression predicts opposition to redistribution.

\begin{tabular}{|c|c|c|c|c|}
\hline & $\begin{array}{c}\text { (1) } \\
\text { Main reg. }\end{array}$ & $\begin{array}{c}(2) \\
\text { Normalized } \\
\text { coefficients } \\
\text { from } \\
\text { indirect reg. }\end{array}$ & $\begin{array}{c}\text { (3) } \\
\text { Auxiliary } \\
\text { reg. }\end{array}$ & $\begin{array}{c}\text { (4) } \\
\text { Robustness }\end{array}$ \\
\hline $\begin{array}{l}\text { Belief that wealth is caused } \\
\text { by industriousness }\end{array}$ & $\begin{array}{l}0.522 * * * \\
(0.032)\end{array}$ & -2.123 & $\begin{array}{l}1.118 * * * \\
(0.121)\end{array}$ & $82.1 \%$ \\
\hline White & $\begin{array}{l}0.285^{* * *} \\
(0.036)\end{array}$ & -1.670 & $\begin{array}{l}0.827 * * * \\
(0.141)\end{array}$ & $80.5 \%$ \\
\hline Male & $\begin{array}{l}0.298 * * * \\
(0.030)\end{array}$ & -1.081 & $\begin{array}{l}0.583 * * * \\
(0.120)\end{array}$ & $82.5 \%$ \\
\hline Income/10,000 & $\begin{array}{l}0.027 * * * \\
(0.004)\end{array}$ & 2.392 & & \\
\hline Observations & 3999 & & 3999 & \\
\hline R-squared & 0.13 & & 0.13 & \\
\hline$\hat{\sigma}_{K}$ & & & 13.58 & \\
\hline
\end{tabular}

See notes to Table 7. 
Table 10. Robustness statistics for selected values of $\alpha_{K-1}^{*}$ other than zero.

\begin{tabular}{llll}
\hline \hline & Model 1 & Model 2a & Model2b \\
\hline$\alpha_{K-1}^{*}=.5 \alpha_{K-1}$ & $53.7 \%$ & $85.6 \%$ & $77.9 \%$ \\
$\alpha_{K-1}^{*}=.75 \alpha_{K-1}$ & $38.9 \%$ & $82.9 \%$ & $70.6 \%$ \\
\hline
\end{tabular}


Table A1. Bounds on current income and $x_{K-1}$ (see Table 1 for definitions of $x_{K-1}$ in each model.)

\begin{tabular}{|c|c|c|c|c|c|c|}
\hline & \multicolumn{2}{|c|}{ Model 1} & \multicolumn{2}{|c|}{ Model 2a } & \multicolumn{2}{|c|}{ Model 2b } \\
\hline & $\begin{array}{l}\text { Bounds on } \\
\text { current } \\
\text { income }\end{array}$ & $\begin{array}{l}\text { Bounds on } \\
x_{K-1}\end{array}$ & $\begin{array}{l}\text { Bounds on } \\
\text { current } \\
\text { income }\end{array}$ & $\begin{array}{l}\text { Bounds on } \\
x_{K-1}\end{array}$ & $\begin{array}{l}\text { Bounds on } \\
\text { current } \\
\text { income }\end{array}$ & $\begin{array}{l}\text { Bounds on } \\
x_{K-1}\end{array}$ \\
\hline $\begin{array}{l}1^{\text {st }} \text { set of } \\
\text { bounds }{ }^{\mathrm{a}}\end{array}$ & 0.033 & 0.062 & 0.033 & 0.611 & 0.027 & 0.522 \\
\hline $\begin{array}{l}2^{\text {nd }} \text { set of } \\
\text { bounds }{ }^{b}\end{array}$ & 0.138 & $1.798 \mathrm{e}^{-07}$ & 1.865 & 0.061 & 0.494 & $4.542 \mathrm{e}^{-05}$ \\
\hline $\begin{array}{l}3^{\text {rd }} \text { set of } \\
\text { bounds }{ }^{c}\end{array}$ & $9.441 \mathrm{e}^{-08}$ & 0.944 & 0.003 & 7.148 & $2.343 \mathrm{e}-06$ & 2.130 \\
\hline
\end{tabular}

${ }^{a}$ Numbers shown are coefficients from the direct regression of opposition to redistribution on the regressors.

${ }^{b}$ Numbers shown are normalized coefficients obtained by estimating the indirect regression of current income on opposition to redistribution and the other regressors and then solving for opposition to redistribution on the left hand side.

${ }^{c}$ Numbers shown are normalized coefficients obtained by estimating the indirect regression of the proxy for expected future income on opposition to redistribution and the other regressors and then solving for opposition to redistribution on the left hand side. 